\title{
GROUND RADAR POLARIMETRIC OBSERVATIONS OF HIGH-FREQUENCY EARTH-SPACE COMMUNICATION LINKS
}

\author{
Steve Bolen ${ }^{1}$, V. Chandrasekar ${ }^{2}$ and Andrew Benjamin ${ }^{1}$
}

\begin{abstract}
Strategic roadmaps for NASA's Human Exploration and Development of Space (HEDS) enterprise support near-term highfrequency communication systems that provide moderate to high data rates with dependable service. Near-earth and human planetary exploration will baseline $\mathrm{K}_{\mathrm{a}}$-Band, but may ultimately require the use of even higher frequencies. Increased commercial demand on low-frequency earth-space bands has also led to increased interest in the use of higher frequencies in regions like $\mathrm{K}_{\mathrm{u}}$ - and $\mathrm{K}_{\mathrm{a}}$ band. Data is taken from the Tropical Rainfall Measuring Mission (TRMM) Precipitation Radar (PR), which operates at $13.8 \mathrm{GHz}$, and the true radar reflectivity profile is determined along the PR beam via low-frequency ground based polarimetric observations. The specific differential phase $\left(\mathrm{K}_{\mathrm{dp}}\right)$ is measured along the beam and a theoretical model is used to determine the expected specific attenuation $(k)$. This technique, called the $k-\mathrm{K}_{\mathrm{dp}}$ method, uses a Fuzzy-Logic model to determine the hydrometeor type along the PR beam from which the appropriate $k$ - $\mathrm{K}_{\mathrm{dp}}$ relationship is used to determine $k$ and, ultimately, the total path-integrated attenuation (PIA) on PR measurements. Measurements from PR and the NCAR S-POL radar were made during the TEFLUN-B experiment that took place near Melbourne, FL in 1998, and the TRMM-LBA campaign near Ji-Parana, Brazil in 1999.
\end{abstract}

\footnotetext{
${ }^{1}$ NASA/Johnson Space Center, EV, Houston, TX

${ }^{2}$ Colorado State University, Fort Collins, CO

This paper is declared a work of the U.S. Government and is not subject to copyright protection of the United States.
}

\section{INTRODUCTION}

Multipolarimetric ground radar (GR) observations can be used to quantify the pathintegrated-attenuation (PIA) experienced by high-frequency space radar systems. This analysis can be used to infer attenuation on earth-space communication links. Observations from ground-based polarimetric radars have been previously used to study the effects of a precipitating medium on radio wave propagation along earth-space paths using satellite-based beacon data. A few of these studies are described by Beaver and Bringi (1997). In rain medium, Bringi, et. al. (1990) showed that attenuation is nearly linearly proportional to differential phase shift $\left(\phi_{\mathrm{dp}}\right)$ at microwave frequencies. A similar relationship between specific attenuation $(k)$ and specific differential phase $\left(\mathrm{K}_{\mathrm{dp}}\right)$ is presented to determine the two-way PIA along a space radar beam.

Inter-comparisons between ground radar and space radar measurements are, in principle, straightforward. However, consideration of numerous details are important to proper alignment of radar observations from two distinct platforms that have different viewing aspects, operating frequencies and resolution volume sizes (Bolen and Chandrasekar, 2001)

Simultaneous measurements were collected between ground and space radars during the TExas and FLorida UNderflights (TEFLUN-B) field campaign on August 13, 1998 near Melbourne, FL and the Large Biosphere-Atmosphere experiment in Amazonia (LBA) on February 25, 1999 near Ji-Parana, Brazil. Data was selected based on 
coincident observations between the two systems when significant meteorological echoes were present. Comparisons are made between the $k-K_{d p}$ method and the current single-frequency attenuation correction algorithm used by the TRMM Precipitation Radar (PR). Measurements between the PR and ground radar are aligned, and an example inter-comparison along a PR beam is performed using data from the TRMM-LBA case. Applications to space-based communication systems are also presented.

\section{$\underline{k-K_{\text {dp }} \text { THEORETICAL MODEL }}$}

Theoretical modeling was performed to determine the relationship between the specific attenuation $(k)$ of a nearly vertical pointing $\mathrm{K}_{\mathrm{u}}$-band spaceborne radar system with measurements of the specific differential phase $\left(\mathrm{K}_{\mathrm{dp}}\right)$ taken from a nearly horizontal pointing ground radar, as shown in Figure 1. The T-Matrix method (Waterman, 1971) is used to determine the scattering properties for ten different hyrdrometeor types along the space radar beam: drizzle (dr), rain (rn), lowdensity ice crystals (li), high-density ice crystals (hi), wet ice crystals (wi), dry graupel (dg), wet graupel (wg), small hail (hs), large hail (hl) and rain mixed with hail (rh). The hydrometeor size distribution (HSD) for each

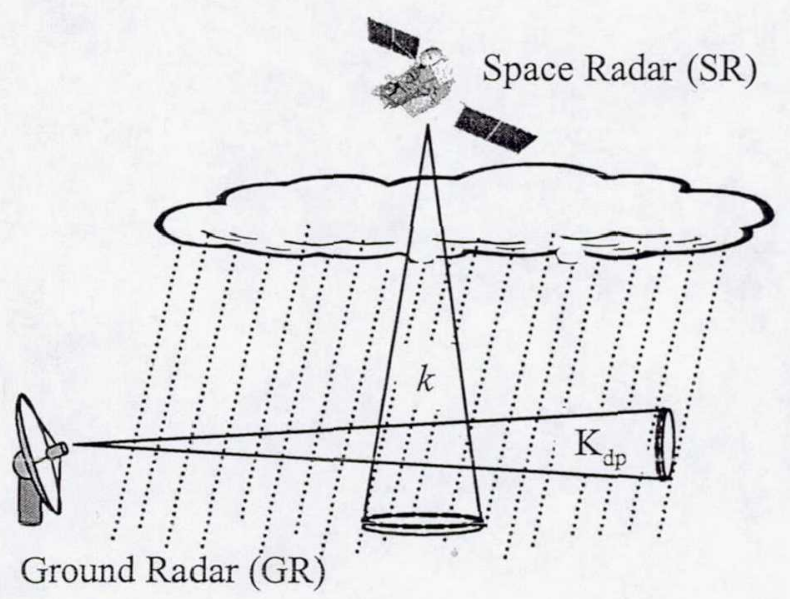

Figure 1: Illustration of measurement geometry. class type is assumed to be of the form (Ulbrich, 1983):

$$
N(D)=N_{o} D^{\mu} e^{-\Lambda D} \quad m^{-1} m^{-3}
$$

with $\mathrm{D}(\mathrm{mm})$ being the hydrometeor diameter and $\mu$ the shaping factor. When plotted on semi-logarithmic axis the distribution becomes a straight line with intercept $N_{0}$ $\left(\mathrm{mm}^{-1} \mathrm{~m}^{-3}\right)$ and slope $\Lambda\left(\mathrm{mm}^{-1}\right)$. The intercept parameter can also be expressed as:

$$
N_{\mathrm{o}}=\mathrm{N}_{\mathrm{w}} f(\mu) \mathrm{D}_{\mathrm{o}}^{-\mu}
$$

where $D_{0}$ is the median diameter and, for rain, (with $\Gamma$ as the gamma function)

$$
f(\mu)=\frac{6}{(3.67)^{4}} \frac{(3.67+\mu)^{\mu+4}}{\Gamma(\mu+4)}
$$

Additionally, particles are assumed to be rotationally and equatorially symmetric with orientation canting angles. The HSD parameters $\left(N_{w}, D_{0}\right.$ and $\left.\mu\right)$ were varied according to the values available in the literature: drizzle as per Sauvegot (1992); rain as per Gorgucci, et. al., (2000); low-density ice crystal and wet ice crystal as per Passarelli (1978); high-density ice crystal as per Beheng (1978); graupel, wet and dry, as per Bringi, et. al. (1997); and hail as per Cheng and English (1983). The rain-hail mixture was determined from simultaneous inputs of both rain and hail hydrometeors to the simulation. It is noted that with the exception of rain, all other HSD's have $\mu$ set equal to zero.

An example scatter plot of the theoretical relationship between S-band horizontally pointing $\mathrm{K}_{\mathrm{dp}}$ vs. $\mathrm{K}_{\mathrm{u}}$-band vertically pointing $k$ for rain is shown in Figure 2. From this plot, it can be seen that the $k-K_{d p}$ relationship for rain is nearly linear with slope, $c_{\text {rain }}=1.96$ $\mathrm{dB} / \mathrm{deg}$. Similar relationships for the other 
hydrometeor types are summarized in Table 1.

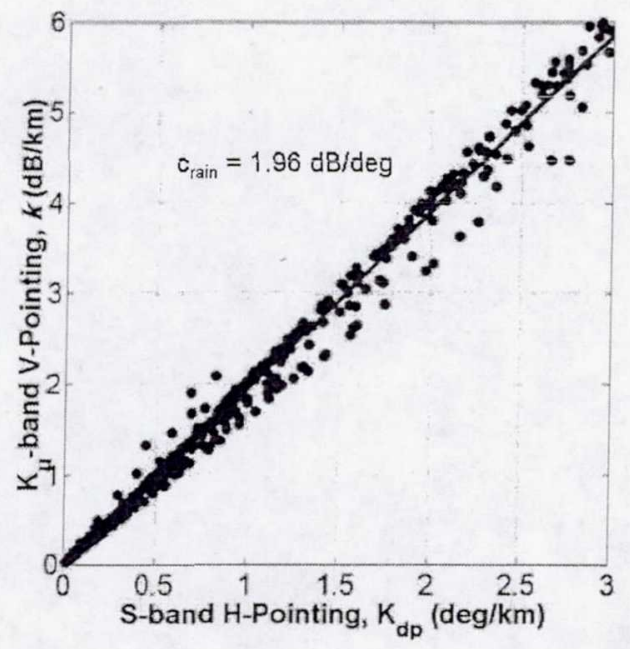

Figure 2: Example of $k-\mathrm{K}_{\mathrm{dp}}$ relationship for rain.

\begin{tabular}{|c|c|c|c|c|c|c|c|c|c|c|}
\hline & $\mathrm{dr}$ & $\mathrm{rn}$ & li & $\bar{h}$ & $w$ & $\mathrm{dg}$ & $\mathrm{wc}$ & $\mathrm{hs}$ & $\mathrm{hl}$ & $\mathrm{rh}$ \\
\hline 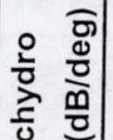 & 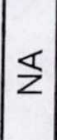 & 官 & $z$ & $\Sigma$ & $\stackrel{N}{\circ}$ & 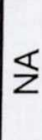 & 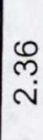 & $\underset{\sim}{\stackrel{N}{+}}$ & $\stackrel{\text { N̦ }}{\stackrel{2}{2}}$ & $\hat{m}$ \\
\hline
\end{tabular}

Table 1: Mean relationship between $k$ and $\mathrm{K}_{\mathrm{dp}}$ for various hydrometeor types.

\section{GR AND SR MATCHING}

Inter-comparisons between ground and space radar (SR) data can be a challenging task. Differences in viewing aspects, operating frequencies and resolution volume size can produce errors in direct comparisons between the two systems. Geometric distortion introduced into the space radar image, due to the movement and attitude perturbations of the satellite itself, further complicate the problem of alignment and comparison (Schowengerdt, 1997).

Potential first order errors are minimized by collecting ground and space data during simultaneous intervals not exceeding 2-3 minutes in time difference. Furthermore, small areas $(50 \times 50 \mathrm{~km})$ are typically defined around a region of interest to minimize nonlinear distortion effects. Both sets of data are re-mapped to a satellite-centered Cartesian coordinate system using a non-spherical earth model (WGS-84 model); GR re-sampling also uses a 4/3-earth radius model to compensate for beam refraction. The vertical and horizontal extents of both GR and SR beams at a given location are used to define a 3dimensional volume that encloses both GR and SR resolution volumes (Meneghini and Kozu, 1990), thus "matching" the two radar resolutions volumes in spatial extent, as shown in Figure 3. Lastly, a polynomial distortion model technique is used (Schowengerdt, 1997) to reduce relative geometric distortions between GR and SR images. The final result is a set of coincident GR and SR measurements that are aligned and matched in resolution.

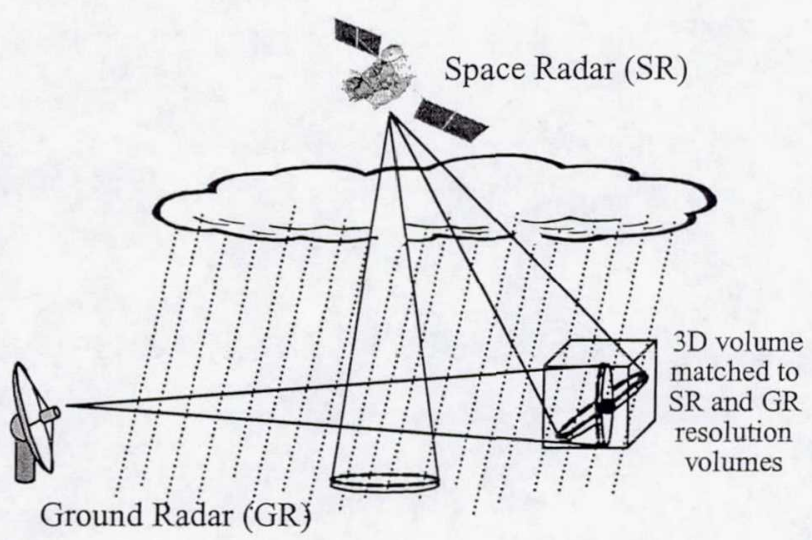

Figure 3: Illustration of radar resolution volume matching.

\section{ATTENUATION ESTIMATE}

After resolution cell matching and alignment, ground radar observations of $\mathrm{K}_{\mathrm{dp}}$ were taken along the TRMM PR beam from data collected during the TRMM-LBA field campaign. The hydrometeor type was determined along the beam path via a Fuzzylogic technique (Liu and Chandrasekar, 2000) 
using ground-based polarimetric observations. The appropriate $k-\mathrm{K}_{\mathrm{dp}}$ relationship was then applied along the beam and the specific attenuation determined. The two-way PIA at each point along the path is calculated from:

$$
\operatorname{PIA}(s)=\int_{\mathrm{r}=0}^{\mathrm{s}} \overline{\mathrm{c}}_{\text {hydro }} \mathrm{K}_{\mathrm{dp}}(\mathrm{r}) \mathrm{dr}
$$

where $s$ is the beam slant range distance starting from the cloud top at $\mathrm{r}=0$ and $\overline{\mathrm{c}}_{\text {hydro }}$ is the mean-weighted $k-\mathrm{K}_{\mathrm{dp}}$ relationship, determined from theoretical modeling, for each of the hydrometeor types in the matched resolution cell. The PR reflectivity corrected for attenuation is given by:

$$
\mathrm{Z}_{\mathrm{m}}(\mathrm{PR} ; k \text {-corrected })=\mathrm{Z}_{\mathrm{m}}(\mathrm{PR})+\mathrm{PIA} .
$$

An example of attenuation correction along a single PR beam is presented using the TRMM LBA case. A horizontal cross-section of reflectivity of the storm cell taken at $2 \mathrm{~km}$ altitude is shown in Figure 4. The location of the PR beam is indicated by the circle, which represents the footprint of the radar at this

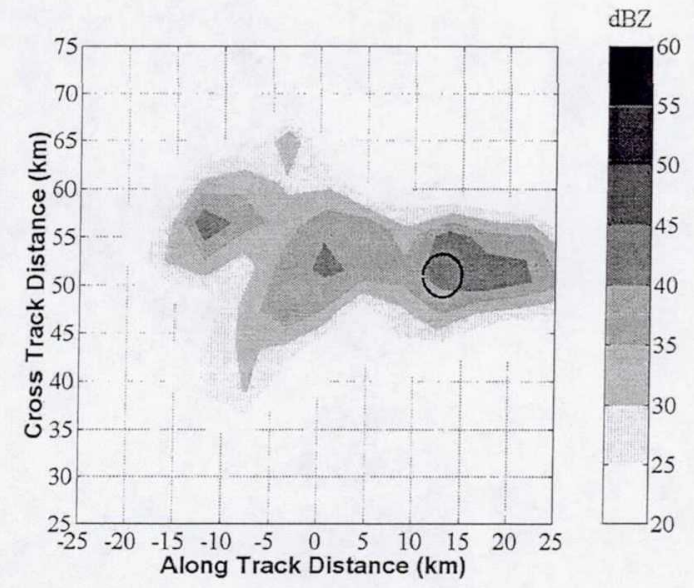

Figure 4: Horizontal cross-section of GR reflectivity at $2 \mathrm{~km}$ altitude. PR footprint indicated by the circle drawn to scale. altitude and is drawn to scale. The vertical profile of reflectivity is shown in Figure 5 with the PR beam shown as solid lines (drawn to scale). The freezing height level and PR clutter altitude (certain), as derived from PR processing algorithms, are also shown in Figure 5.

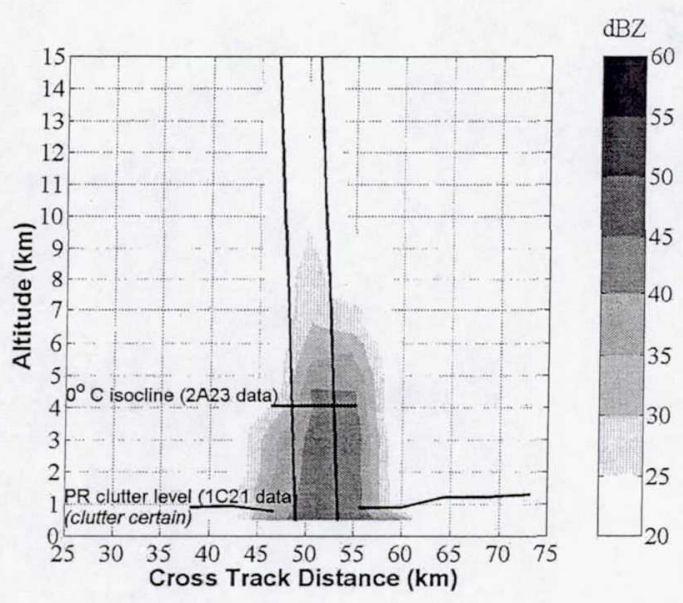

Figure 5: Vertical cross-section of GR reflectivity with PR beam shown by solid lines drawn to scale.

The $k$-corrected PR reflectivity, the measured GR reflectivity, $Z_{\mathrm{m}}(\mathrm{GR})$, measured $P R$ reflectivity, $Z_{m}(P R)$, and $P R$ attenuation corrected reflectivity from the current $P R$ attenuation correction algorithm, $\mathrm{Z}_{\mathrm{c}}(\mathrm{PR})$, as well as ground radar polarimetric measurements of linear depolarization ratio (LDR), cross-correlation coefficient $\left(\rho_{\mathrm{co}}\right)$, specific differential phase $\left(\mathrm{K}_{\mathrm{dp}}\right)$ and differential reflectivity $\left(\mathrm{Z}_{\mathrm{dr}}\right)$, along the $\mathrm{PR}$ beam are shown in Figure 6. In this figure, attenuation is seen to be nearly $10 \mathrm{~dB}$ on PR reflectivity measurements, relative to GR measurements. PR attenuation corrected reflectivity (derived from the PR processing algorithm) slightly under-estimates the attenuation with reference to the $Z_{\mathrm{m}}(\mathrm{GR})$ vertical profile. The $k$-Kdp corrected reflectivity (shown as a solid line) more closely matches the vertical $Z_{\mathrm{m}}(\mathrm{GR})$ profile. 


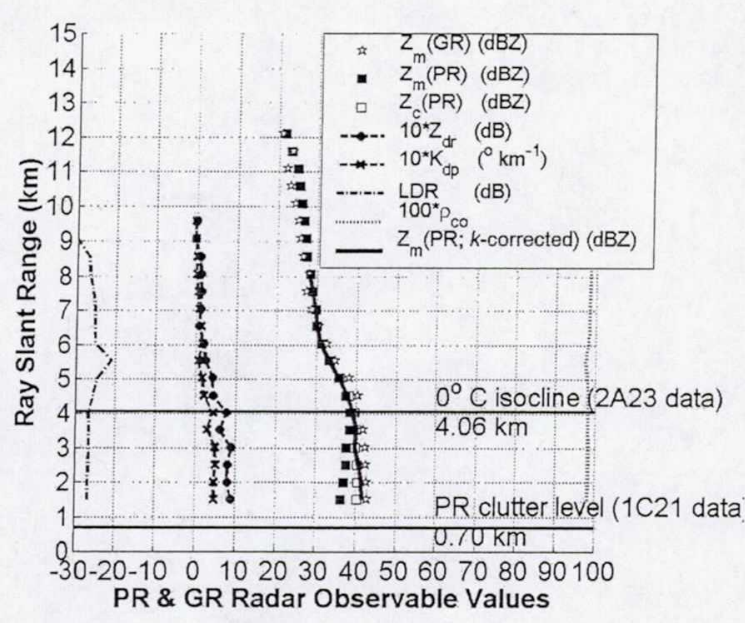

Figure 6: PR measurements, GR polarimetric measurements, and $k$ - $\mathrm{K}_{\mathrm{dp}}$ corrected $\mathrm{PR}$ reflectivity along PR beam for TRMM-LBA data on February 25, 1999.

\section{COMMUNICATIONS APPLICATIONS}

Open loop attenuation estimation from a network of ground-based polarimetric radars can be used in site-diversity schemes for commercial spot-beam satellite systems, such as those used in the cellular mobile industry. Maps of attenuation estimates derived from the $k-\mathrm{K}_{\mathrm{dp}}$ method can be used near scheduled ground sites to determine link quality due to precipitation signal degradation, and links can be dynamically routed based on the attenuation maps. Effects of the precipitating medium on the $\mathrm{K}_{\mathrm{u}}$-band link used for preflight test and checkout of Space Shuttle Orbiter (SSO) systems, from the JSC ESTL facility, can be performed prior to the test. Quality assessment can also be made on direct data links from low earth orbit (LEO) satellites supporting other NASA enterprises such as the meteorological science missions in the Earth Science Enterprise (ESE). Attenuation estimates can be used to adjust optimum power levels for signal transmission.

\section{SUMMARY}

Attenuation effects on high-frequency earth-space communication systems can be significant. A method for quantitatively determining the attenuation of space-based signals, using individual space radar beams, and ground-based polarimetric observations has been presented. A theoretical model was developed to determined the relationship between high-frequency spaceborne specific attenuation with ground-based $K_{d p}$ observations for ten different hydrometeor types. The PIA was then calculated along the beam. The method was validated by applying it to in-situ data collected during the TEFLUN-B and TRMM-LBA field campaigns. It was found that, under certain circumstances, the $k$ - $\mathrm{K}_{\mathrm{dp}}$ method for attenuation correction performed better than the current correction algorithm being used by the TRMM PR data products, and that attenuation could be as high as $10 \mathrm{~dB}$.

\section{ACKNOWLEDGEMENTS}

Acknowledgement is made to the NASA Tropical Rainfall Measuring Mission (TRMM) Program.

\section{REFERENCES}

Beaver, J. and Bringi, V., The Application of S-Band Polarimetric Radar Measurements to $\mathrm{K}_{\mathrm{a}}$-Band Attenuation Prediction, Proceedings of the IEEE, 85, no. 6, 893909, 1997.

Beheng, K., Numerical Simulation of Graupel Development, J. Atm. Sci., 35, pp 683-689, 1978.

Bringi, V., Chandrasekar, V., Balakrishnan, N. and D. S. Zrnic, D. S., An Examination of Propagation Effects in Rainfall on Radar Measurements at Microwave Frequencies, J. of Atm. and Oceanic Tech., 7, no. 6, pp 829-830, 1990.

American Institute of Aeronautics and Astronautics 
Bolen, S. and Chandrasekar, V., Methodology for Comparing Spaceborne Radar with Ground-Based Radar Observations, publication pending, 2002.

Bolen, S. and Chandrasekar, V., Quantitative Cross Validation of Space-Based and GroundBased Radar Observations, J. Appl. Meteorol.Special Issue on TRMM, 39, pp 2071-2079, 2000.

Bringi, Knupp, K., Detwiler, A., Liu, L., Caylor, I and Black, R., Evolution of a Florida Thunderstorm during the Convection and Precipitation /Electrification Experiment: The Case of 9 August 1991, Mthly Wthr Rev, 125, pp 2131-2160, 1997.

Cheng, L. and English, M., A Relationship Between Hailstone Concentration and Size, 40, J. Atm. Sci., pp 204-213, 1983.

Gorgucci, E., Scarchilli, G.,Chandrasekar, V.,and Bringi, V.,Spatial Distribution of Mean Raindrop Shape from Polarimetric Radar Observations, Proc $13^{\text {th }}$ Inter Conf. on Clouds \& Precip.,1,pp361-363, 2000.

Liu, H. and Chandrasekar, V., Classification of Hydrometeors Based on Polarimetric Radar Measurements: Development of Fuzzy Logic and Neuro-Fuzzy Systems, and In Situ Verification, J. Atm. Oceanic Tech., 17, pp 140-164, 2000.

Meneghini, R. and Kozu, T., Spaceborne Weather Radar, Artech House, Inc., Norwood, MA,1-3,26-27, 1994.

Passarelli, R.,Theoretical and Observational Study of Snow-Sized Spectra and Snowflake Aggregation Efficiencies, $J$. Atm. Sci.,35,pp882-889, 1978.
Sauvageot, H., Radar Meteorology, Artech House, Inc, Norwood, MA, 150, pp 167170, 1992.

Schowengerdt, R., Remote Sensing Models and Methods for Image Processing, $2^{\text {nd }}$ Ed., Academic Press, San Diego, CA, pp 331-337, 1997.

Ulbrich, C. W., Natural variations in the analytical form of raindrop size distributions, J. Climate Appl. Meteor., 22, pp 1764-1775, 1983.

Waterman,P., Symmetry,Unitarity,and Geometry in Electromagnetic Scattering, Phy Rev, D3, pp 825-839, 1971 